\title{
Crushing Mechanism for Soil Particles
}

\author{
Masayuki Oishi' ${ }^{1}$, Yoshihiro Kubota2 ${ }^{2}$, Osamu Mochizuki ${ }^{3}$ \\ ${ }^{1}$ Daiki Rika Kogyo Co., Ltd., Kōnosu, Japan \\ ${ }^{2}$ Department of Mechanical Engineering, Toyo University, Saitama, Japan \\ ${ }^{3}$ Graduate School of Science and Engineering, Toyo University, Saitama, Japan \\ Email: *kubota548@toyo.jp
}

How to cite this paper: Oishi, M., Kubota, Y. and Mochizuki, O. (2020) Crushing Mechanism for Soil Particles. World Journal of Mechanics, 10, 69-82.

https://doi.org/10.4236/wjm.2020.106006

Received: June 9, 2020

Accepted: June 25, 2020

Published: June 28, 2020

Copyright $\odot 2020$ by author(s) and Scientific Research Publishing Inc. This work is licensed under the Creative Commons Attribution International License (CC BY 4.0).

http://creativecommons.org/licenses/by/4.0/

(c) (i) Open Access

\begin{abstract}
Typically, soil samples must be crushed into particles for laboratory research. Thus, an efficient mechanism to ensure a uniform particle size is essential. We previously developed a rod mill device that performs well, but video analysis indicated that the shear forces applied by the rod were more effective than the compressive forces applied by the mill. The mechanism for this phenomenon is unclear. This study focused on clarifying the relationship between compressive load and abrasion when crushing dried and hardened soil particles. Soil pellets of the same size were prepared, and model experiments were performed, where vertical compression and abrasion were applied to the pellets until they fractured. The results showed that soil pellets were fractured easily when an abrasive load was continuously applied in the circumferential direction. Additionally, the load required to fracture the soil pellets was much lower than the required vertical compressive load. The rod mill device was previously thought to fracture soil aggregates by gradually stripping soil particles away from the surface. However, our experimental results clarified that the fracture process started at the center and subsequently induced the entire pellet's sudden failure.
\end{abstract}

\section{Keywords}

Rod Mill, Soil Aggregate, Breaking, Load Test, Abrasion

\section{Introduction}

This is the study to understand the crushing mechanism quantitatively for the development of rod mill device for soil. When a soil sample is examined at a research institute, the soil must first be crushed into fine-grained particles, with a median diameter of less than $2 \mathrm{~mm}$, to satisfy industrial standards. This crushed material consists of a large amount of aggregated soil, with great variability in 
size and hardness. Thus, a mechanism for grinding the soil efficiently is needed. Several methods have been devised, including human-powered methods, using a pestle, mortar, and sieves, as well as mechanical methods, where a rod or ball is rotated against the soil being crushed. Crushing is intended to reduce the size of a solid and has a broad meaning. It covers breaking ores and other solids as well as the fine crushing of grains and seeds. Soil is an aggregate, consisting of a combination of soil particles, and the crushing and sizing of soil (i.e., sieving and classification) for chemical analysis differs from breaking or fine crushing soil that must be separated into particles less than, or equal to, a desired size. In other words, if the force holding the soil particles together is removed, they fall apart.

We have proposed a rod mill device, in which a rod is turned inside a container holding the soil to be crushed. This device can crush, dry, and harden soil aggregates in a short time. The necessary factors for improving device performance further were obtained by comparing the soil aggregates' yield stresses and the forces acting on them within the container. We visualized the action of the rod and soil aggregates during the crushing process using a high-speed camera installed in the container [1]. Video footage showed that the rod within the container first struck the aggregated soil surface, and the particle bonds loosened from the surface inward, resulting in crushing [2]. Takahashi for scale-up and continuous pulverization of a vibration mill with ring media were promoted for pretreatment of lignocellulose biomass [3]. Results demonstrate that filling the rod media inside the hole of the ring media improved the micronizing efficiency in large amounts of Japanese cedar powder and increased the saccharification efficiency during the initial stage of pulverization. As a result, it was shown that the higher the number of crushing rods, the higher the crushing efficiency in crushing a large amount of cedar powder. However, in our rod mill developed exclusively for soil crushing, increasing the number of rods reduced crushing efficiency [1]. Furthermore, the rod mill-based shear force was more effective than the rod mill-based compressive force. However, the process by which friction resulted in fracture, and the relationship between the friction and compressive load, are unclear.

Shear forces are generated when compressive forces are applied to soil particles with varying sizes and morphologies, and slightly elastic behavior has been observed. Defossez and Richard used a finite element method to demonstrate numerically that stress is transmitted into lower layers by applying vertical loads to the soil surface [4]. Cam-Clay models can be used to describe the different soil deformation phases, from elastic deformation to rupture, and recent advances in modeling have led to the development of coupled models that consider mechanical and hydraulic process interactions. Software studies, using discrete element methods (DEM), have shown that rubbing a plate on a single particle of ore material can easily fracture it through the complex stress of tensile shear [5]. This suggests that dried and hardened soil particles can be broken easily when pressed and rubbed against the wall of the rod mill device container. 
Stresses frequently propagate through preferential paths, rather than homogenously, which isolates bulk volumes that are under less stress than the preferential path. This is because different assemblages coexist in soils because of small differences in particle size and shape [6]. When subjected to compression, soil particles initially tend to move elastically. Majmudar and Behringer used experiments and numerical analyses to show that, under external stress, grains in dry granular materials form an inhomogeneous contact network that carries most of the external load through force chains [7]. Furthermore, The Desrues et al. showed that stresses become concentrated in local regions, called shear bands, when plastic deformation or failure is induced by external stresses in heterogeneous solids, such as soil or concrete [8] [9]. With regard to crack formation and propagation processes due to compressive stresses, Izawa et al. performed uniaxial compression experiments on mechanically heterogeneous columnar granite and demonstrated that cracks were generated in the cross-section center and propagated vertically through the center [10]. These results mostly agree with numerical analyses based on the mineral distribution method. However, this approach cannot recreate the significantly decreased stress present after failure and crack formation at the vertical ends observed in the experiments.

As particulate matter, soil has complex reactions, and the relationship between individual particles' properties and the material's reaction is not fully understood. Normally, soil is air-dried before it is used for physical and chemical tests. However, dried and hardened soil aggregates do not have uniform sizes and shapes and are, thus, unsuitable for quantitative tests. This study focused on clarifying the relationship between the compressive load and abrasion when crushing dried and hardened soil particles. Soil particles from the same source were prepared into soil pellets of the same size, and a model experiment was performed where varying loads were applied to soil pellets with a resin plate to cause the pellets to fracture. The results indicated that the pellets were destroyed immediately when a crack formed at the circumference toward the center of the pellet.

\section{Soil Model and Experimental Methods}

\subsection{Preparation of Soil Pellet}

The soil used for the soil pellet was collected from the stratum called Kanto Loam which is widely distributed around Tokyo. The Kanto Loam was formed by sedimentation of volcanic ash and volcanic debris which were weathered by wind and rain and has high cohesiveness with $25 \%$ to $40 \%$ contents of silt and clay. The soil pellets used in the experiments were fabricated to ensure uniform mass and morphology. The average soil aggregate volume, when crushed with a rod mill device, is $1 \times 10^{-6} \mathrm{~m}^{3}$; thus cylindrical soil pellets with a diameter of $1 \times$ $10^{-2} \mathrm{~m}$ and length of $1 \times 10^{-2} \mathrm{~m}$ were formed for the experiments, as shown in Figure 1. Figure 2 shows the kit we used to form the soil pellets for this experiment. Figure 3 shows the formation procedure, which is detailed below: 


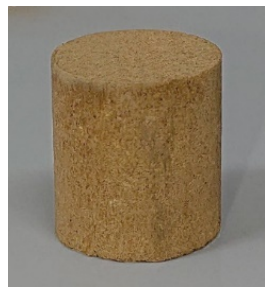

Figure 1. Soil pellet.

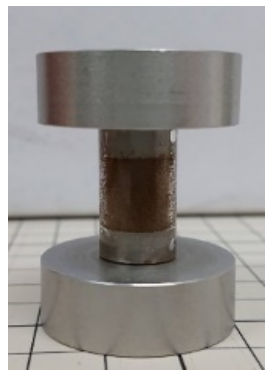

Figure 2. Soil pellet production kit. Soil is pressed in the cylinder.

Place $1 \times 10^{-3} \mathrm{~kg}$ of soil in the acrylic pipe.

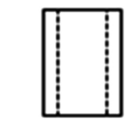

Acrylic

pipe

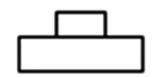

Stand

Step 1.

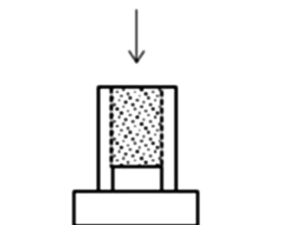

Step 2.

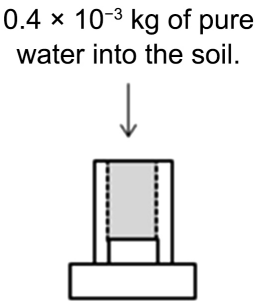

Step 3.

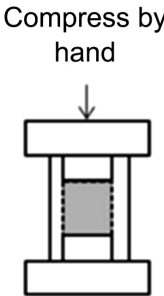

Step 4.

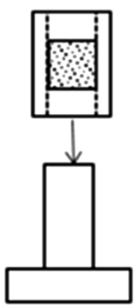

Step 6.

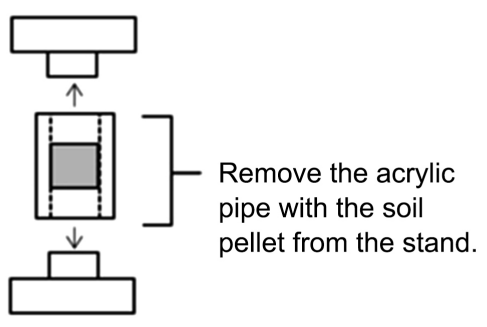

Step 5.

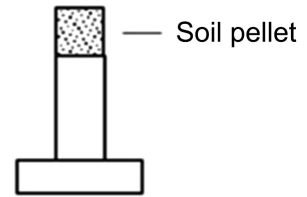

Step 7.

Figure 3. Steps to make soil pellet. 
Step 1: Insert an acrylic cylinder with an inner diameter of $1 \times 10^{-2} \mathrm{~m}$ and length of $2 \times 10^{-2} \mathrm{~m}$ into a convex stainless steel stand with a diameter of $1 \times$ $10^{-2} \mathrm{~m}$ and height of $5 \times 10^{-3} \mathrm{~m}$. Place the cylinder and stand on an electronic scale and zero the balance.

Step 2: Place $1 \times 10^{-3} \mathrm{~kg}$ of soil in the acrylic cylinder.

Step 3: Gradually pour $0.4 \times 10^{-3} \mathrm{~kg}$ of pure water into the soil and allow it to penetrate.

Step 4: Insert another stainless steel stand into the acrylic cylinder from above and compress by hand.

Step 5: Remove the acrylic cylinder from the stands and place the cylinder in an air dryer for approximately $15 \mathrm{~min}$.

Step 6: Remove the soil pellet from the acrylic cylinder by inserting a convex stainless steel stand with a diameter of $1 \times 10^{-2} \mathrm{~m}$ and length of $2 \times 10^{-2} \mathrm{~m}$.

Step 7: Once the soil pellet is removed from the acrylic cylinder, dry the soil pellet to $1 \times 10^{-3} \mathrm{~kg}$ before using it in the test.

\subsection{Soil and Physical Mass of the Pellets}

A soil particle density test (JIS A 1202) and soil moisture content test (JIS A1203) were conducted on the volcanic ash-derived soil used to manufacture the soil pellets. (JIS is an abbreviation for the Japan Industrial Standard.) Table 1 shows the test results. Soil pellets were manufactured by mixing $1 \times 10^{-3} \mathrm{~kg}$ (standard deviation $=0.537$ ) of soil (containing moisture) and $0.4 \times 10^{-3} \mathrm{~kg}$ of pure water (standard deviation $=0.124$ ), placing the mixture in an acrylic cylinder, and compressing it. To prevent the soil pellet's water content from affecting experimental results, a pellet that had been dried naturally for 48 hours was used as the experimental sample. Next, the physical masses of the soil pellet were determined to determine the void ratio (e). In general, soil is a three-phase system, consisting of solid (soil grains), liquid, and gaseous matter. Thus, each soil pellet was made of soil grains, water, and air. The physical masses for soil grains $\left(m_{s}\right)$, water $\left(m_{w}\right)$, and air $\left(m_{a}\right)$ were calculated using the average values of 100 soil pellets. The soil pellet mass $m$ is thus defined as

$$
m=m_{s}+m_{w}+m_{a}
$$

and the water content $w$ is defined as

$$
w=\frac{m_{w}}{m_{s}} \times 100 .
$$

Table 1. Soil particle density test and soil moisture content test of the volcanic ash-derived soil.

\begin{tabular}{cc}
\hline Soil Test Items & Test Results \\
\hline Soil particle density $\left(\rho_{s}\right) \mathrm{g} / \mathrm{cm}^{3}$ & 2.432 \\
Natural water content $(w) \%$ & 17.70 \\
Void ratio $(e) \%$ & 1.720 \\
\hline
\end{tabular}


The soil pellet mass $m=1.02 \times 10^{-3} \mathrm{~kg}$, and the air mass in Equations (1) and (2) can be assumed to be 0 . Thus, $m_{s}=0.862 \times 10^{-3}$ and $m_{w}=0.153 \times 10^{-3} \mathrm{~kg}$. These results can be used to determine soil pellet volume. The soil pellets were 1 $\times 10^{-2} \mathrm{~m}$ in diameter and $1 \times 10^{-2} \mathrm{~m}$ in length, yielding a soil pellet volume of $0.785 \times 10^{-6} \mathrm{~m}^{3}$. The relationship between the soil pellet volume $(v)$ and the volumes of the solid $\left(v_{s}\right)$, water $\left(V_{w}\right)$, and air $\left(v_{a}\right)$ is given by

$$
v=v_{s}+v_{w}+v_{a} .
$$

The soil particle density $\rho_{s}$ is 2.432 , as shown in Table 1 .

$$
\rho_{s}=\frac{m s}{V s}
$$

Thus, $V_{s}=0.354 \times 10^{-6} \mathrm{~m}^{3}, V_{m}=0.153 \times 10^{-6} \mathrm{~m}^{3}$.

$$
v_{a}=v-v_{s}+v_{w}
$$

Based on the soil pellet volume $v=0.785 \times 10^{-6} \mathrm{~m}^{3}$ and Equation (5), $v_{a}=$ $0.251 \times 10^{-6} \mathrm{~m}^{3}$.

The void ratio $e$ is given by

$$
e=\frac{v_{a}+v_{w}}{v_{s}} \times 100
$$

Thus, the soil pellets had an $e$ value of 1.141. Table 1 indicates that e decreased from 1.720 to 1.141 when the test results and soil pellets' physical properties were compared. However, this may be because the air volume between soil particles was reduced by compression when the pellets were formed. In this way, the soil pellets have the same shape and size, and the physical masses of the grains $\left(m_{s}\right)$, water $\left(m_{w}\right)$, and air $\left(m_{a}\right)$ that they are made of are also made homogeneous. These are determined from the value of real soil. This means that the experiment can be carried out to understand quantitatively.

\subsection{Breaking Tests with a Vertical Load}

Figure 4 shows a pressing test using an unconfined compression test device (Instron 5566) to investigate the force needed to fracture a soil pellet. The device's upper table was dropped onto the lower table, onto which the soil pellet was placed, at a rate of $1 \mathrm{~mm} / \mathrm{min}$, and a vertical load was applied in the circumferential direction of the soil pellet. Load changes were measured, with the load cell attached to the lower table, when the upper table contacted the soil pellet. Further compression in the vertical direction by the upper table resulted in the soil pellet fracturing. Ten pieces of soil aggregates and 50 pieces of soil pellets were randomly selected and measured to compare the yield stress and corresponding displacement.

\subsection{Breaking Tests with a Reciprocating Rotary Load Test Device}

To reproduce the breaking of soil pellets due to abrasion, an experiment was performed with the reciprocating rotary load test device shown in Figure 5. 


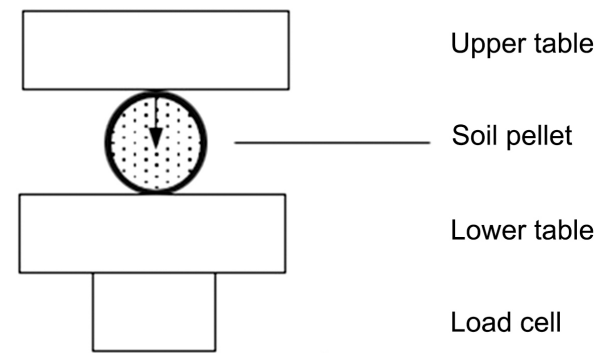

Figure 4. Compressive load test method.

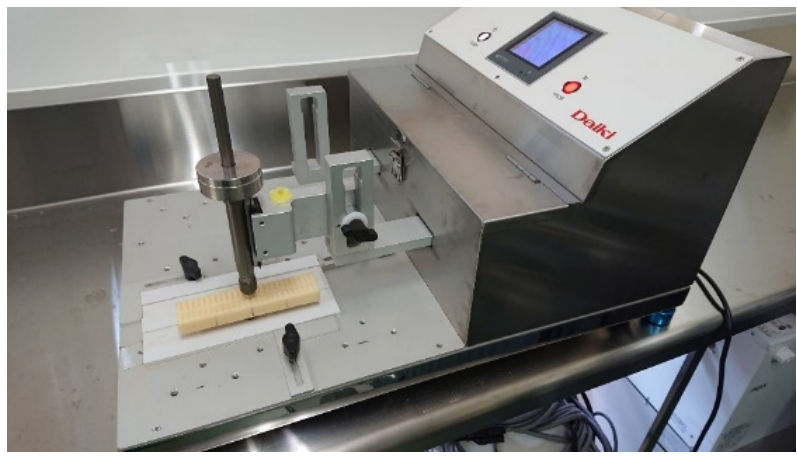

Figure 5. Reciprocating rotary load test device.

Table 2 lists the reciprocating rotary load test device specifications. As shown in Figure 6, the reciprocating rotary load test device consisted of a mechanism that allowed the slide arm to move freely up and down and a resin cantilever plate with a width, length, and thickness of $30 \mathrm{~mm}, 130 \mathrm{~mm}$, and $14 \mathrm{~mm}$, respectively, that was attached to the lower part of the slide arm. This allowed a constant load to be applied to the test object by a weight attached to the upper part of the arm. A soil pellet was placed on a rail plate $100 \mathrm{~mm}$ wide and $180 \mathrm{~mm}$ long with a $1 \mathrm{~mm}$ deep indentation in the lengthwise direction. The movement distance of the holding plate was set to $120 \mathrm{~mm}$, and the reciprocating cycle was set to $0.17 \mathrm{~Hz}$ (i.e., 10 reciprocations per minute). The load from the weight, applied at the contact between the cantilever and the soil pellet, is added evenly over the pellet's circumference as it rotates.

The soil pellet was subjected to abrasion by a holding plate at five load levels with the reciprocating rotary load test device. The holding plate's movement distance was set to $120 \mathrm{~mm}$, and the reciprocating cycle was set to $0.17 \mathrm{~Hz}$ (i.e., 10 reciprocations per minute). As the holding plate reciprocated in the horizontal direction, the soil pellet rotated counterclockwise and clockwise on the rail plate. Because of the rolling principle, the movement distance of the soil pellet was $60 \mathrm{~mm}$, which was half that of the holding plate. The soil pellet revolved approximately twice per reciprocation. The coefficient of static friction between the soil pellet and the rail plate was 0.44 . As in the reciprocating rotary load test, the rolling friction coefficient of the soil pellet's rotating surface (peripheral surface) was 0.05 for both the rail and holding plates, and the shear force was negligible. The load was changed in five stages and applied to ten soil pellets at each stage. 
Table 2. Reciprocating rotary load test device specifications.

\begin{tabular}{cc}
\hline & Specifications \\
Travel distance & $120 \mathrm{~mm}$ \\
Reciprocating speed & 10 times $/ \mathrm{min}$ \\
Power supply & AC $100-240 \mathrm{~V}, 50 / 60 \mathrm{~Hz}$ \\
Dimensions & W380 $\mathrm{mm} \times \mathrm{D} 590 \mathrm{~mm} \times 310 \mathrm{~mm}$ \\
Equipment weight & Approx. $22 \mathrm{~kg}$ \\
\hline
\end{tabular}

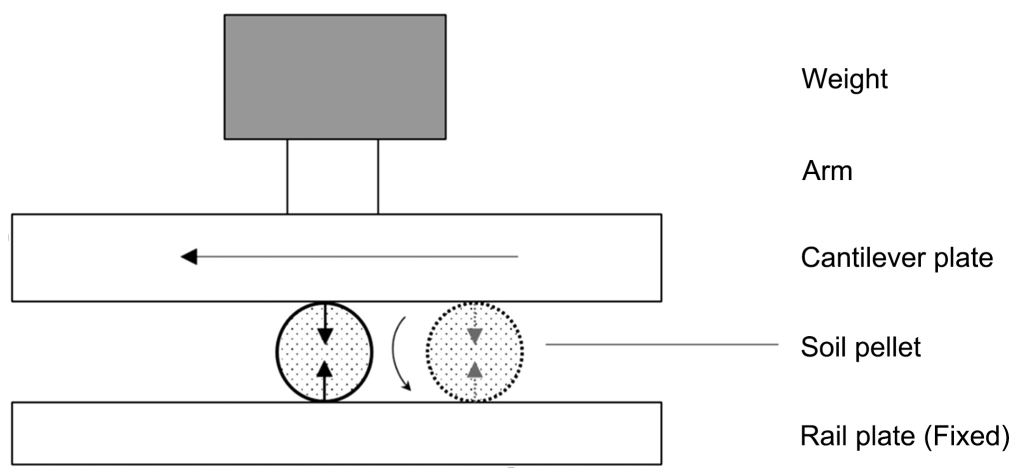

Figure 6. Reciprocating rotary load test device. The soil pellet is rotated by the arm with a cantilever plate. The force from the weight acts on the center of the soil pellet through the pellet's circumference as it rotates.

The number of revolutions of each soil pellets was measured until breakage occurred.

\section{Results and Discussion}

\subsection{Yield Stress of Soil Pellets}

We conducted unconfined compressive tests to study the yield stress at which the soil pellet fractured to determine its homogeneity and strength. The yield stress was measured by a corresponding displacement to investigate the amount of force needed to fracture the soil pellet using the Instron 5566. The measured values of the maximum yield stress are shown in the plot in Figure 7 . The average yield stress of 50 soil pellets was $0.88 \times 10^{-3} \mathrm{~kg}$, with a standard deviation of $0.25 \times 10^{-3} \mathrm{~kg}$. It was found that $94 \%$ of the soil pellets had compression stresses in the range of $13 \mathrm{~N}$ to $31 \mathrm{~N}$, and the corresponding compressive strain $(\varepsilon)$ values at the yield stress were in the range of 0.006 to 0.009 .

The $\varepsilon$ values were calculated by the following formula.

$$
\varepsilon=\frac{\Delta H}{H_{0}}
$$

Here, $\Delta H$ is the change of vertical displacement of upper table and $H_{0}$ is the initial diameter of the soil pellet.

In contrast, the size and mass of air-dried soil aggregates vary naturally when 


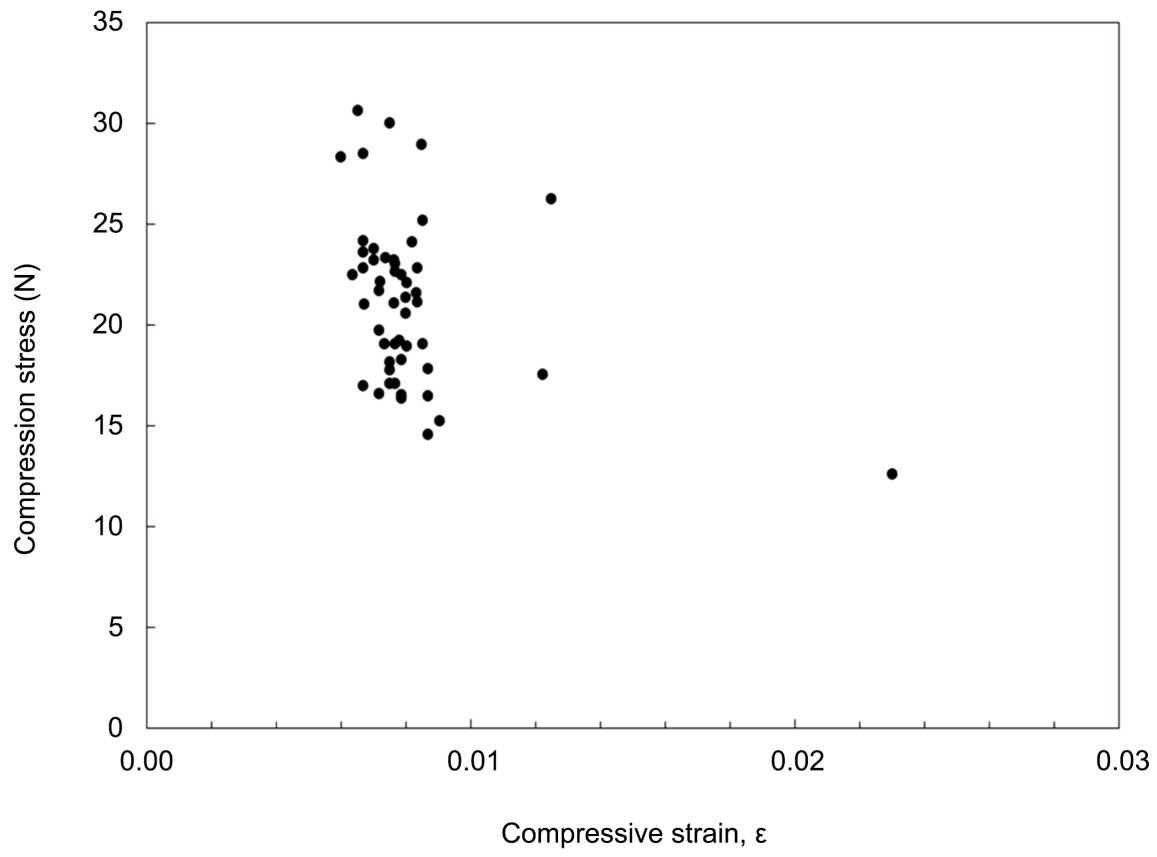

Figure 7. Compressive strain at the yield points of various soil pellets.

fractured in ordinary situations. Soil aggregates are groups of soil particles that bind more strongly with each other than with adjacent particles. The yield point and strain of the air-dried soil aggregates were measured, using an unconfined compressive test device. The average and the standard deviation obtained from these measurements are shown in Table 3. The mass, yield stress, and yield point strain of individual soil aggregates varied widely, and there was no strong correlation between the measured results.

\subsection{Soil Pellet Breakage in the Compression Test}

Figure 8 shows the breaking process of a soil pellet in the unconfined compression test device. The graph represents the load and displacement of the soil pellet as it fractured, with corresponding breaking process points indicated by photos (a) to (c). In photo (a), the compressive stress showed a peak at $24 \mathrm{~N}$ ( $\varepsilon=$ 0.0094). A distinct vertical crack was confirmed in the center of the pellet. In photo (b), the pellet was split into two pieces at $19 \mathrm{~N}(\varepsilon=0.015)$. In photo (c), each separate piece was broken further at $18 \mathrm{~N}(\varepsilon=0.020)$. For each session, soil pellets responded to the vertical compressive load by cracking from the center in the vertical direction.

Regarding this elastic behavior, Mütze derived a stress behavior model in which particle bed stress behavior was such that the particles moved into interstitial spaces, and individual particles formed elasticity at low pressure levels, whereas, at higher pressure levels, the stress behavior model led to fracture [11]. Wang and Yan used 3D DEM simulation results to demonstrate that particle breakage disrupts the strain energy buildup at small strains, thus reducing the mobilized shear strength and dilatancy of a granular soil [12]. 
Table 3. Compressive strain and maximum yield stresses of air-dried soil aggregates.

\begin{tabular}{cccc}
\hline $\begin{array}{c}\text { Number of samples } \\
\mathrm{n}=10\end{array}$ & $\begin{array}{c}\text { Air-dried soil } \\
\text { aggregate mass Kg }\end{array}$ & $\begin{array}{c}\text { Maximum yield } \\
\text { stress } \mathrm{N}\end{array}$ & $\begin{array}{c}\text { Compressive strain } \\
\mathcal{E}\end{array}$ \\
\hline Average & $0.86 \times 10^{-3}$ & 52 & 0.17 \\
Standard deviation & $0.23 \times 10^{-3}$ & 36 & 0.037 \\
\hline
\end{tabular}

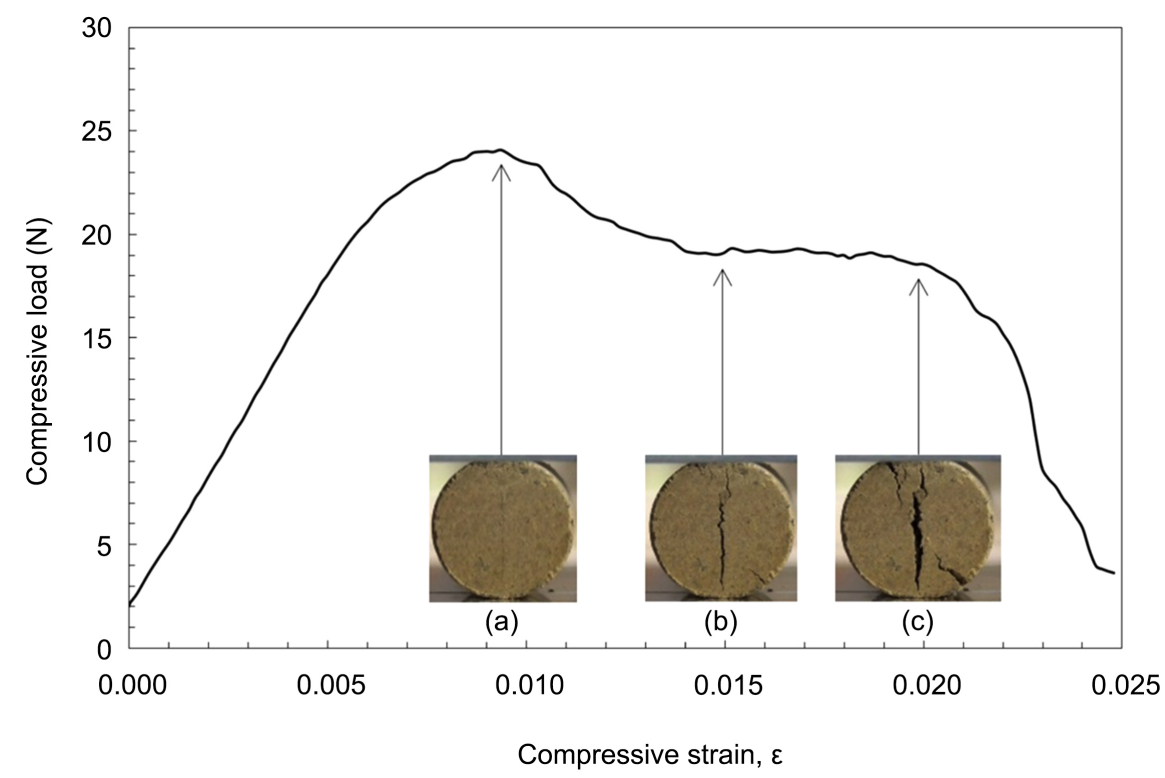

Figure 8. Breakage process of a soil pellet during a compression test. (a) A distinct vertical crack develops in center of the pellet. (b) The soil pellet is split into two pieces. (c) Each piece was broken further.

The soil pellet bulged slightly in the horizontal direction until the vertical load displacement reached the maximum yield stress. Until reaching this point, the soil pellet acted as an elastic body. In both the aggregated soil and the soil pellets used in the normal test, when the vertical load displacement reached the maximum yield stress, large cracks split the soil lumps. However, it did not break into small lumps (particles) at once, which would occur in a crushing container.

\subsection{Soil Pellet Breakage in the Reciprocating Rotary Load Test}

Figure 9 shows a series of photos of disintegrating soil pellets. It took only 1 second from the start of collapse to complete collapse. This instantaneous disintegration is consistent with the disintegration in the container of the rod mill equipment. Figure 10 shows the breakage process of the soil pellet during the reciprocating rotary load tests. Illustrations are presented below the images as a supplement. Figure 10(a) shows a soil pellet 10 rotations after the start of an experiment with a load of $8 \mathrm{~N}$. A crack can be seen at the center of the soil pellet, and the size of this crack increased after rotation 11, as shown in Figure 10(b). Multiple cracks formed 13 rotations after the start of the experiment, as shown in Figure 10(c). The soil pellet completely fractured after 15 rotations. 

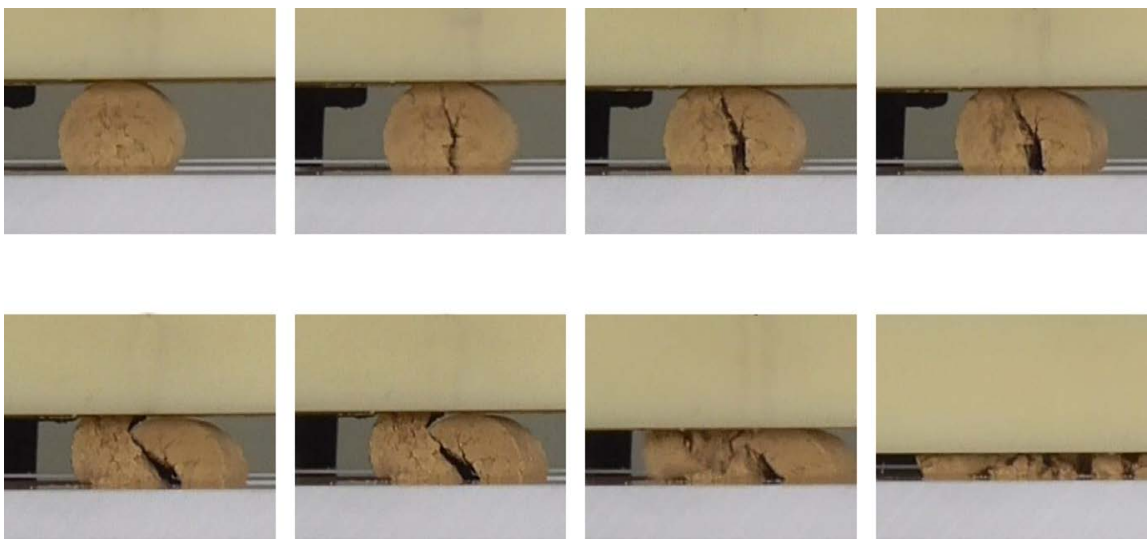

Figure 9. A series of photos of disintegrating soil pellets. It took only 1 second from the start of collapse to complete collapse.
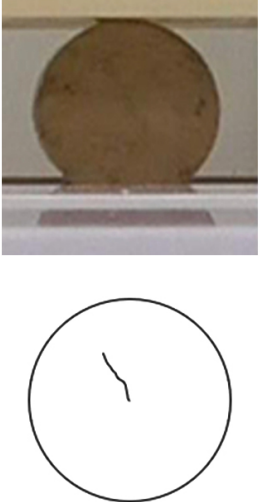

(a)
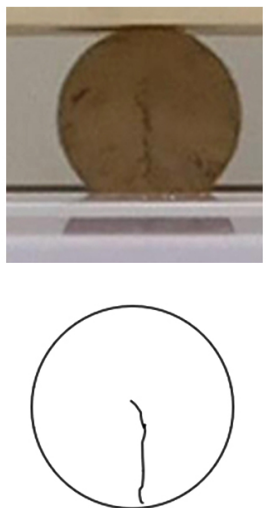

(b)
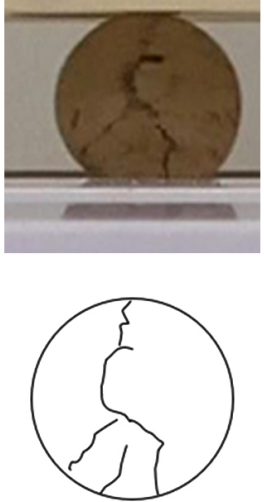

(c)

Figure 10. Crack development in a soil pellet undergoing a reciprocating rotary load test with a load of $8 \mathrm{~N}$. (a) 10 rotations after the start of the experiment. A crack can be seen at the center; (b) 11 rotations after the start of the experiment. The size of the crack has increased; (c) 13 rotations after the start of the experiment. Multiple cracks have formed.

The reciprocating rotary test results are shown in Figure 11. The vertical axis shows the number of rotations needed for a soil pellet $(R m)$ to break and the horizontal axis shows the load $(W)$. As described earlier, the average vertical compression, without reciprocating rotation, needed to fracture a soil pellet is $21 \mathrm{~N}$, at which point the soil particles' cohesiveness could be reduced (i.e., broken apart). This indicates that the load needed with reciprocating rotary loads is in the range of $1 / 3$ to $1 / 5$ of the vertical load compression.

Furthermore, it is understood that the number of rotations needed for breakage to occur decreases as the load increases. In other words, as the load increases, less time is needed for the pellet to break (i.e., fewer rotations). The correlation coefficient between the load and the average number of rotations required to break the soil pellet was 0.9353 , meaning it was closely correlated to the inverse proportion. This demonstrated the relationship between the mass of the rod that crushed the soil mass in the container and the rotational speed of the container in the rod mill. In the previous research, the aggregated soil mass 


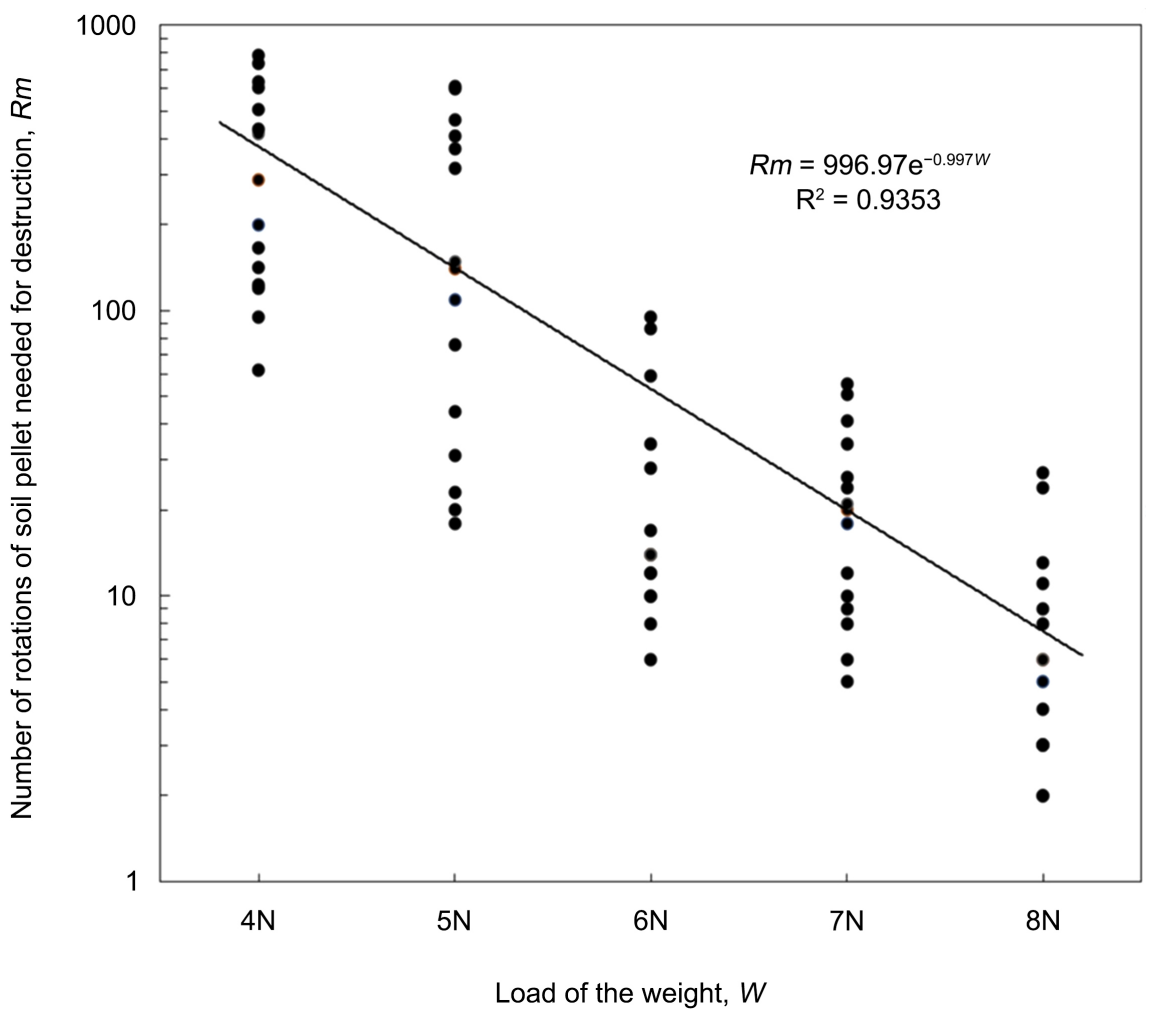

Figure 11. Number of rotations and required load for soil pellet destruction.

used for the normal crushing test had a distorted shape, so it was a test in which the cantilever contacted only part of the fixed state. However, the soil in the container of the crushing device is rubbed against the crushing rod and the container while the soil is also rotating intricately due to the rotation of the container and the complicated movement of the crushing rod. This experiment using soil pellets is believed to be able to simulate the behavior occurring in these real crushing containers.

In the reciprocating rotary load test at $8 \mathrm{~N}$, the soil pellets broke from the center, as they did in the compression test. We also observed the breaking process at $4 \mathrm{~N}$ in detail. Figure 12(a) shows a side surface of a soil pellet at the initial stage of a reciprocating rotary load test with a load of 4 N. Figure 12(b) shows a magnified view of the side surface of the soil pellet after being rotated 140 times. No significant change was observed on the side surface of the soil pellet with an unaided eye. However, when observed under magnification by digital microscope (HDGMCSPwh made by PlumRive), there was a small crack connecting the center of the pellet from the circumferential direction and a part of the outer periphery was also chipped. After 165 rotations, the soil pellet was completely broken, with large cracks, as in the case of the $8 \mathrm{~N}$ load. A reciprocating rotary load test was shown to break soil pellets with less stress than what is required to break soil pellets with an unconfined compression device. The unconfined compression device only applies a vertical load to the soil pellet, whereas, in the reciprocating rotary load device, the soil pellet is rotated to apply 


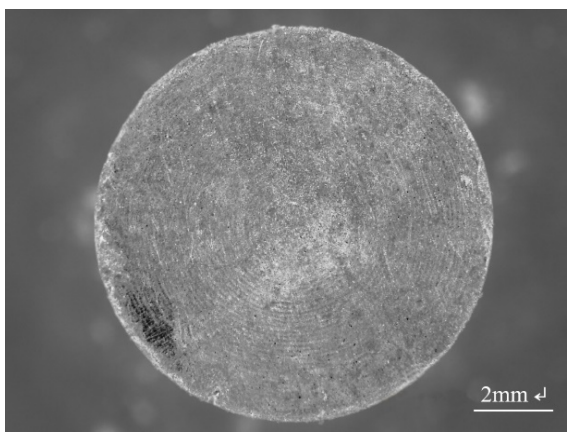

(a)

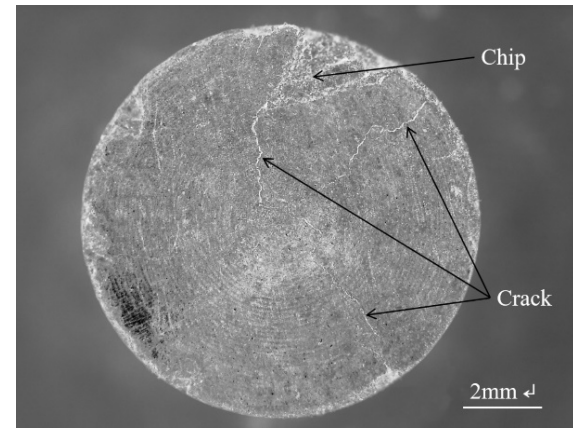

(b)

Figure 12. Side surface of a soil pellet initially and after 140 rotations in a continuous rotation load test with a weight of $4 \mathrm{~N}$. (a) Initial condition; (b) After 140 rotations.

a dynamic load to the contact point in the circumferential direction. Applying a static load and a dynamic load in the circumferential direction reduces the bond strength between soil particles, a crack is generated between the soil particles inside the soil pellet, and the soil pellet systematically ruptures.

\section{Conclusions}

To examine the breakage of dried and hardened soils, we performed model experiments on soil pellets of equal size, soil quality, and particle size to clarify the relationship between compressive loads and friction.

Our conclusion is listed as below:

1) Soil pellets were used in the experiments to disclose how collapse dried and hardened soils.

2) Soil pellets were all made of equal size, soil quality, and particle size to clarify the relationship between compressive loads and friction.

3) Soil pellets were fractured easily when loads were applied continuously in the circumferential direction.

4) The loads necessary for fracture on a soil pellet was smaller than when using vertical compressive loads.

5) In the experiment by using a rod mill device, soil particles were gradually stripped away from the aggregate surface.

6) The fracture process of soil pellets started at the center of the aggregate and subsequently induced the sudden failure of the entire aggregate.

7) It is concluded from the experiments that the rotation of the soil pellets caused disintegration (breakage and collapse) of themselves.

\section{Acknowledgements}

We wish to thank the basic physical data of soil pellet by the General Building Research Corporation of Japan (GBRC) and large number of compression test of soil pellet by the Saitama Industrial Technology Center (SAITEC). Funding for the development of rod mill from the Saitama Prefecture is gratefully acknowledged. 


\section{Conflicts of Interest}

The authors declare no conflicts of interest regarding the publication of this paper.

\section{References}

[1] Oishi, M., Kubota, Y. and Mochizuki, O. (2019) Investigation of Fundamental Mechanism of Crushing of Clods in a Rod Mill. Engineering, 11, 703-716. https://doi.org/10.4236/eng.2019.1110045

[2] Oishi, M., Kubota, Y. and Mochizuki, O. (2019) Investigation of the Fragmentation Process of Clods in a Rod Mill Developed for Research Use. World Journal of Mechanics, 9, 233-243. https://doi.org/10.4236/wjm.2019.910015

[3] Takahashi, T. (2019) Ring and Rod Media Combination Effects on Continuous Pulverization by Tandem Ring Mill. Journal of the Japan Institute of Energy, 98 , 333-339. https://doi.org/10.3775/jie.98.333

[4] Defossez, P. and Richard, G. (2002) Models of Soil Compaction Due to Traffic and Their Evaluation. Soil and Tillage Research, 67, 41-64. https://doi.org/10.1016/S0167-1987(02)00030-2

[5] Yu, H., Fei, Q., Wang, R., Fan, B., Wang, Y. and Shi, B. (2017) Study on Crushing Mechanism of Cone Crusher. Advances in Computer Science Research, 62, 612-616. https://doi.org/10.2991/jimec-17.2017.132

[6] Nawaz, M.F., Bourrié, G. and Trolard, F. (2013) Soil Compaction Impact and Modelling. A Review. Agronomy for Sustainable Development, 33, 291-309.

https://doi.org/10.1007/s13593-011-0071-8

[7] Majmudar, T.S. and Behringer, R.P. (2005) Contact Force Measurements and Stress Induced Anisotropy in Granular Materials. Nature, 435, 1079-1082.

https://doi.org/10.1038/nature03805

[8] Desrues, J. and Chambon, R. (2002) Shear Band Analysis and Shear Moduli Calibration. International Journal of Solids and Structure, 39, 3757-3776. https://doi.org/10.1016/S0020-7683(02)00177-4

[9] Desrues, J. and Viggiani, G. (2004) Strain Localization in Sand: An Overview of the Experimental Results Obtained in Grenoble Using Stereophotogrammetry. International Journal for Numerical and Analytical Methods in Geomechanics, 28, 279-321. https://doi.org/10.1002/nag.338

[10] Izawa, S., Ogata, S., Yasuhara, H., Kinoshita, N. and Kishida, K. (2020) Evaluation of Fracture Evolution of Granite during Brazilian Test by Numerical Analysis of Fracturing Process Considering Mineral Distribution. Journal of the Society of Materials Science Japan, 69, 236-242. (In Japanese) https://doi.org/10.2472/jsms.69.236

[11] Mütze, T. (2016) Modelling the Stress Behaviour in Particle Bed Comminution. International Journal of Mineral Processing, 156, 14-23. https://doi.org/10.1016/j.minpro.2016.05.010

[12] Wang, J. and Yan, H. (2012) DEM Analysis of Energy Dissipation in Crushable Soils. Soils and Foundations, 52, 644-657.

https://doi.org/10.1016/j.sandf.2012.07.006 